\title{
ASSESSING 3D PHOTOGRAMMETRY TECHNIQUES IN CRANIOMETRICS
}

\author{
M. C. Moshobane \\ ${ }^{a}$ Invasive Species Program, South African National Biodiversity Institute, Kirstenbosch Research Centre, Cape Town, South \\ Africa-moshobanemc@gmail.com \\ ${ }^{\mathrm{b} C e n t r e ~ f o r ~ I n v a s i o n ~ B i o l o g y, ~ D e p a r t m e n t ~ o f ~ B o t a n y ~ a n d ~ Z o o l o g y, ~ S t e l l e n b o s c h ~ U n i v e r s i t y, ~ M a t i e l a n d ~ 7602, ~ S o u t h ~ A f r i c a ~}$ \\ 'Mammal Research Institute, Department of Zoology and Entomology, University of Pretoria, Private Bag X20, Hatfield, \\ 0028, South Africa- (mnbester, pjdebruyn)@ zoology.up.ac.za
}

Youth Forum

KEY WORDS: 3D Modelling, Arctocephalus, Craniometrics, Fur Seal, Photogrammetry, Photomodeler, Photomodelling, Research Techniques.

\begin{abstract}
:
Morphometrics (the measurement of morphological features) has been revolutionized by the creation of new techniques to study how organismal shape co-varies with several factors such as ecophenotypy. Ecophenotypy refers to the divergence of phenotypes due to developmental changes induced by local environmental conditions, producing distinct ecophenotypes. None of the techniques hitherto utilized could explicitly address organismal shape in a complete biological form, i.e. threedimensionally. This study investigates the use of the commercial software, Photomodeler Scanner ${ }^{\circledR}\left(\mathrm{PMSc}{ }^{\circledR}\right)$ threedimensional (3D) modelling software to produce accurate and high-resolution 3D models. Henceforth, the modelling of Subantarctic fur seal (Arctocephalus tropicalis) and Antarctic fur seal (Arctocephalus gazella) skulls which could allow for 3D measurements. Using this method, sixteen accurate 3D skull models were produced and five metrics were determined. The 3D linear measurements were compared to measurements taken manually with a digital caliper. In addition, repetitive measurements were recorded by varying researchers to determine repeatability. To allow for comparison straight line measurements were taken with the software, assuming that close accord with all manually measured features would illustrate the model's accurate replication of reality. Measurements were not significantly different demonstrating that realistic 3D skull models can be successfully produced to provide a consistent basis for craniometrics, with the additional benefit of allowing non-linear measurements if required.
\end{abstract}

\section{INTRODUCTION}

Marine environments are complex, dynamic and therefore in a continuous state of change. Unlike some terrestrial environments, marine systems are not always easy to study due to inaccessibility of both the ocean and the organisms that inhabit it. The need to understand changes in species abundance (whether natural or man-induced) is acutely recognised (Croxall and Prince 1979) and long-term studies can reveal important information about changes in these environments. Marine mammals, such as pinnipeds (Bester and Van Jaarsveld 1994), show geographical morphological variability. These variations are directly related to their varying environments (Poroshin et al. 2010). Postnatal skull ontogeny is subjected to several environmental factors (Wigginton and Dobson 1999), this aids in understanding not only geographical variations in population's phenotype, but also their life history strategies and evolutionary changes (Lu 2003).

Craniometric measurements represent an effective tool for studying the difference in morphology of mammal populations (Gauthier et al. 2003). New morphometric methodological approaches are effective in capturing reliable information about the shape of an organism and result in powerful statistical procedures for testing differences in shape (Rohlf and Marcus 1993). There is increasing evidence that the improvements of 3D reconstruction methodologies will aid in 3D morphometrics studies (Zollikofer and Ponce de León 2002; Claude et al. 2003; Sholts et al. 2010; Chiari and
Claude 2011; McLean et al. 2012; Ifflaender et al. 2013). The actual bio ${ }^{1}$ logical materials (specimens) are not linear as used to be visualized in traditional methods, and the modern techniques such as 3D modelling could be more effective in enabling a researcher to visualize differences in shape (Rohlf and Marcus 1993). The size, shape and length comparison of the organism are best captured in 3D configuration of homologous land marks.

One of the most active fields of research in morphometrics focuses on the representation of biological specimens in a $3 \mathrm{D}$ configuration. The development of approaches towards digitizing and modelling of these specimens into 3D replicas (Rohlf and Bookstein 1990). The size of the object and $2 \mathrm{D}$ configuration were found to be limiting the reliability and effectiveness of the then digitizing tools. These tools worked well with larger objects and could only transform a 3D biological object into a 2D form (Becerra et al. 1993; Marcus et al. 1993). The common practice of calliper 2D measurement of objects implies that the $3^{\text {rd }}$ dimension has no special biological meaning (Zelditch et al. 2004). Such reduction may lead to loss of some relevant and critical information. This could also lead to compromised and unreliable results for studies such as population variation analysis (Fadda et al. 1997). A better and more comprehensive craniometrics tool is 3D photogrammetry - recording of measurements from 3D specimens' replicas using computer software. Image enhancement techniques may also make it easier to see certain features (Rohlf 1990). Hence, with the availability 
of cost and time effective image acquisition and image analysis software, the recurring limitation could be solved.

The classical approach to morphometrics was further enhanced by the recent advent in the digital methodology of 3D reconstruction that used several types of equipment including: MetraSCAN 3D, MAXscan 3D, touch probe digitizers, optical scanners, computerized axial tomographic imaging, and VIUscan. Even though these tools show relative levels of measuring success, there remain two root causes for potential errors which compromise their accuracy. Firstly, intrinsic error (i.e., the error in reading the laser line or fringe pattern), secondly, errors coming from the positioning device (Claude et al. 2003; van der Niet et al. 2010). Most importantly these techniques are either very costly or require sophisticated instruments rendering them inapplicable in the field (Spencer and Spencer 1995; Fadda et al. 1997; Stevens 1997). A better and more comprehensive craniometrics tool is 3D photogrammetry - recording of measurements from 3D specimens' replicas using computer software.

In this study, we present a photogrammetry based morphometric method using Photomodeler Scanner ${ }^{\circledR}$ software (PMSc $\left.{ }^{\circledR}\right)$ (EOS Systems, Vancouver, http://www.photomodeler.com/index.html) to produce accurate, high-resolution 3D biological model replicas of the skulls. This method allows measurements of the actual biological land marks without reduction or loss of some valuable biological patterns. Based on 1) the density of measurement (from point probing to high-density 3D scanning), 2) portability and ease of use, and 3) accuracy. PMSc ${ }^{\circledR}$ is an accurate method for 3D modelling and measurement recording (Walford 2008). In addition, no decision on which variables should be measured is required in advance and therefore, one can evaluate the usefulness of alternative suites of variables without handling the original specimens again (Rohlf and Marcus 1993). The technique of 3D photogrammetry by $\mathrm{PMSc} \AA$ in morphometrics was successfully used on tortoise carapace (Chiari and Claude 2011) and on horse hoof deformation (Jordan et al. 2001). The study investigated the use of 3D Photogrammetry in craniometrics.

\section{MATERIALS AND METHODS}

Sixteen high-resolution 3D skull models were produced from sixteen skulls (eight for each species, Arctocephalus tropicalis, and Arctocephalus gazella). The species difference in this study was inconsequential, any species can be utilized. The two (coded target and SmartMatch ${ }^{\circledR}$ ) PMSc ${ }^{\circledR}$ tools were used to produce the 3D models. The photograph-based scanning software then compares two photograph based patches of Smart points. Skulls of eight Arctocephalus tropicalis and eight of Arctocephalus gazella were modelled into high-resolution 3D replicas.

\subsection{Data processing}

A close-range photogrammetry calibrated (Fig 1) Kodak Easy share C 195 camera 14 megapixels was used to take photographs. The calibration grid with four corner Ringed Automatically Detected (RAD) coded targets (Fig 1) was printed on an A4 page to suit the project size and type for close-range photogrammetry. This provides accurate calibration of the entire field of view and determines the principal point (at the intersection of photographs and the optical axis of the lens) and compensates for orthogonal distortion and conversion (Remondino and Fraser 2006; de Bruyn et al. 2009). The computer software programme PMSc ${ }^{\circledR}$ was used to create a dense $3 \mathrm{D}$ points cloud and detailed surface models of skulls of the two fur seal species.

\section{Close range photogrammetry}

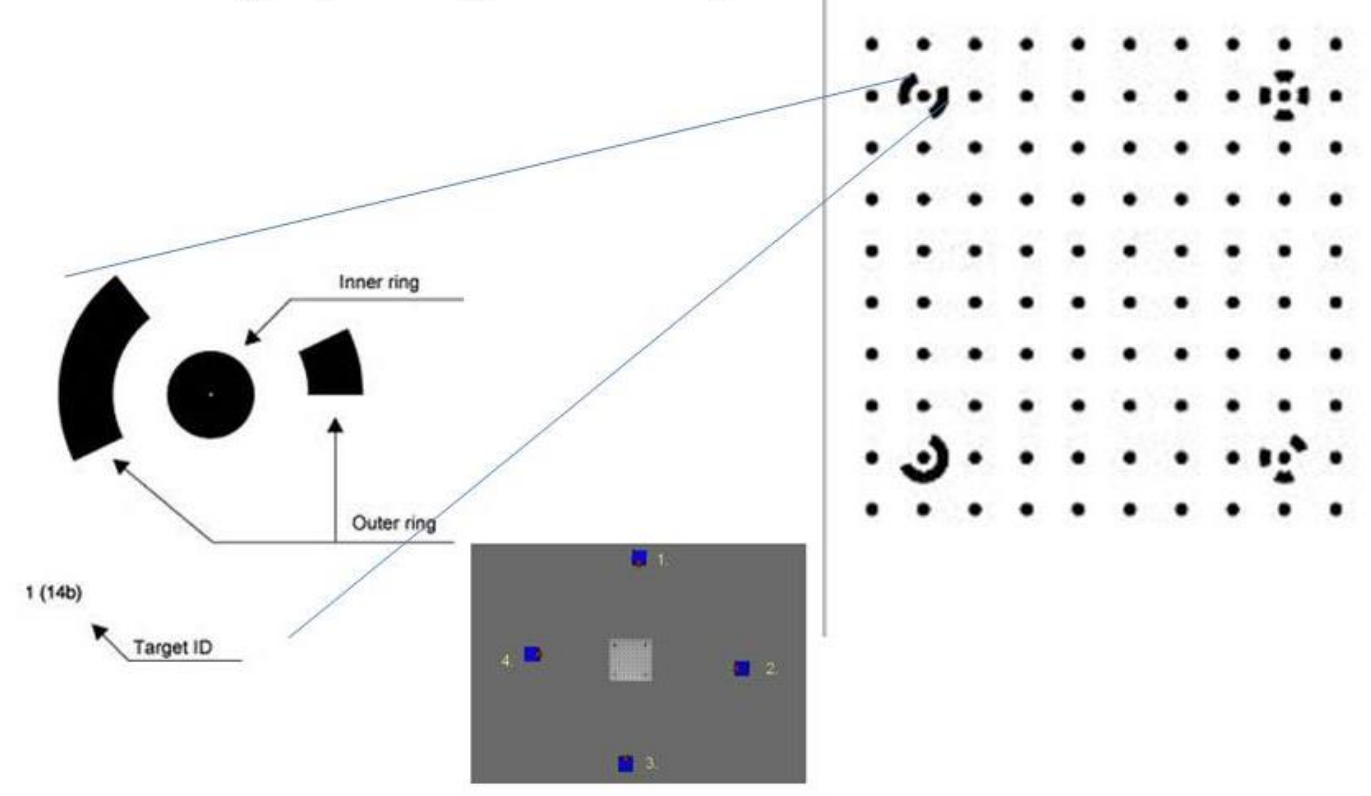

Figure 1. Calibration sheet, used to calibrate the cameras used in the study (see more details in the Photomodeler® help files). 
Coded target and SmartMatch ${ }^{\circledR}$ were used, due to the nature of their automation in 3D capturing and modelling. SmartMatch ${ }^{\circledR}$ automatically cross-reference points on natural features and generates 'Smart Points' to create 3D model while coded target used coded target points. Both methods use a pair of geometric points to produce a dense point cloud model. And use one set of camera calibration. SmartMatch ${ }^{\circledR}$ does not require scaling while the coded target scale was determined using manual referenced points.

The coded target identifies unique RAD coded targets to orientate the cone and skull set-up with reference to each camera position, in three-dimensional space. The photographs are thereby automatically orientated. While the SmartMatch ${ }^{\circledR}$ functionality to automatically crossreference points in a selected area (in this case the skull) and the coded points to create an accurate 3D space. It is also a requirement that the Root Mean Squared (RMS) error should be maintained at $<1.00 \mathrm{~mm}$ residual, meaning that the models will be accurate (Deng and Falg 2001). The area within each photograph occupied by the skull is delineated and a dense point cloud mesh is created as a projection of the skull. The density of points that the software concentrates into this dense point cloud dictates at what pixel resolution the skull can be modelled, and is thus related to the resolution of the camera/lens. Moreover, this serves as a key step in the later identification of skull landmarks for measurement (detailed steps see Photomodeler scanner ${ }^{\circledR}$ software package help files). Measurements were therefore recorded on 3D skull models and compared with traditional caliper measurements.

\section{RESULTS}

\subsection{D Modelling}

Two Photomodeler scanner® software package modelling tools were considered namely, coded target and SmartMatch ${ }^{\circledR}$. Although the models produced by the coded target were acceptable, it was not of sufficient quality to provide desired high resolutions for accurate measurements due to low megapixel coverage per photograph (Fig 4). Only the models produced through the automatic tool (SmartMatch $®$ ) were used for the recording measurements, which were further considered for variance analysis between the two methods, photogrammetry and traditional (caliper), because they were of higher resolution.

\begin{tabular}{|c|c|c|c|c|c|c|c|c|}
\hline \multirow{2}{*}{ Variable } & \multicolumn{2}{|c|}{$\begin{array}{l}\text { Shapiro-Wilk } \\
\text { normality test }\end{array}$} & \multicolumn{2}{|l|}{ F test } & \multicolumn{4}{|c|}{ Kruskal-Wallis rank sum test } \\
\hline & & & $\mathrm{F}$ & & & & & M.y \\
\hline $\begin{array}{l}\text { Condylobasal } \\
\text { length }\end{array}$ & 0.0802 & 0.9411 & 1.0521 & 0.9230 & -0.0255 & \begin{tabular}{|l|l|}
0.9798 \\
\end{tabular} & 225.21 & 225.2 \\
\hline $\begin{array}{l}\text { Supraorbital } \\
\text { width }\end{array}$ & 0.1034 & 0.9449 & 1.0122 & 0.9816 & \begin{tabular}{|l|}
-0.0142 \\
\end{tabular} & 0.9997 & 50.8675 & 50.86 \\
\hline $\begin{array}{l}\text { Braincase } \\
\text { width }\end{array}$ & 0.2668 & 0.9595 & 0.9884 & 0.9823 & -0.0122 & 0.9903 & 57.282 & 57.29 \\
\hline Palatal length & 0.4986 & 0.97 & 1.0312 & 0.9533 & -0.0181 & 0.9856 & 79.093 & 79.13 \\
\hline Ventral width & 0.00215 & 0.8814 & 0.9921 & 0.9879 & N/A & 0.4514 & N/A & N/A \\
\hline
\end{tabular}

Table 1. The Shapiro-Wilk normality test, F test, and Kruskal-Wallis rank sum test results, for five measured variables recorded by caliper and $\mathrm{PMSc} \AA(P=$ Significance, $\mathrm{F}=\mathrm{f}$ value for $\mathrm{f}$ test, $\mathrm{t}=$ value for $\mathrm{t}$-test, $\mathrm{w}=$ value for Shapiro test, M.x = mean for $\mathrm{x}, \mathrm{M} . \mathrm{y}=$ mean for y).

The SPSS software package 21.0 (SPSS Inc. IBM, South Africa) and R software package 2.14.2 (R development Core team 2012) were used to perform basic statistics. The test for normality showed that the data was normally distributed in four variables not the fifth, the vertical width (Table 1). All variables subjected to analysis of variance (F test) between the two methods, caliper, and PMSc ${ }^{\circledR}$ (Table 1), showed no significant differences between the two methods. The normally distributed data for four variables, braincase width (BW), Condylobasal length (CBL), palatal length (PL), supraorbital width (SOW) subjected to Welch Two Sample t-test, and the nonnormally distributed ventral width (VW) subjected to Kruskal-Wallis rank sum test (Table 1), showed that the two methods produced similar results. However, in Boxplot, for CBL (Fig 2) PMSc ${ }^{\circledR}$ is shown to be more sensitive to the variations present. The value of $p$ for all five recorded variables was very high $(0.45$ to 0.99$)$ indicating that the methods produce similar results. Of the five variables used, one (supraorbital process $\mathrm{p}=0.999$ ) showed a very strong factor of similarity, followed by the braincase width $(\mathrm{p}=0.990)$. The PMSc ${ }^{\circledR}$ is sensitive to minute variations as it detects more outliers, which can be identified in CBL comparison. 
The International Archives of the Photogrammetry, Remote Sensing and Spatial Information Sciences, Volume XLI-B6, 2016 XXIII ISPRS Congress, 12-19 July 2016, Prague, Czech Republic

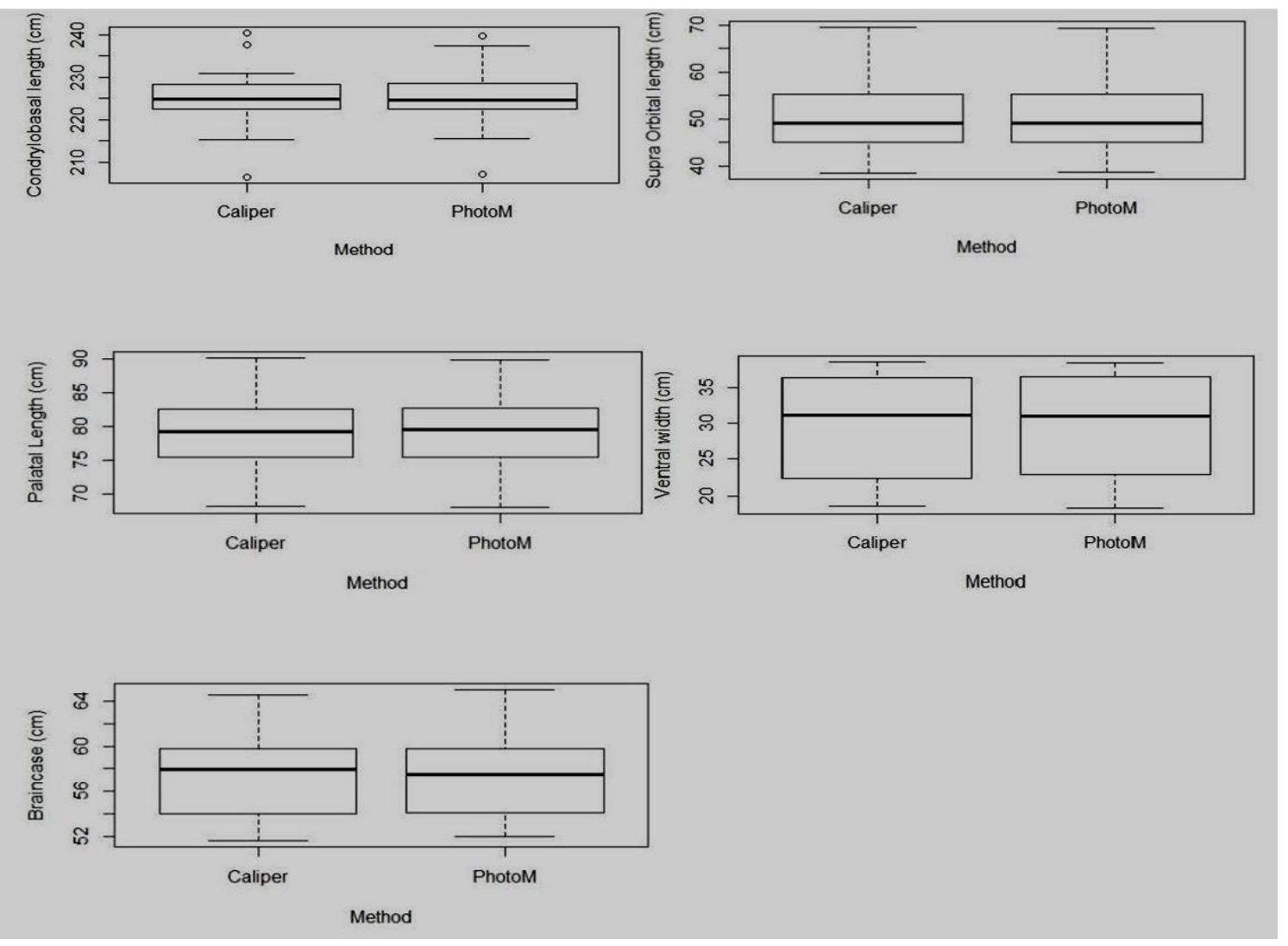

Figure 2. Similarity analysis (F test, Welch Two Sample t-test, Kruskal-Wallis rank sum test ) between PMSc® and Caliper measurements, Median, Interquartile range, and outliers of the measured variables used for the comparison of caliper and 3D PMSc ${ }^{\circledR}$ measurements.
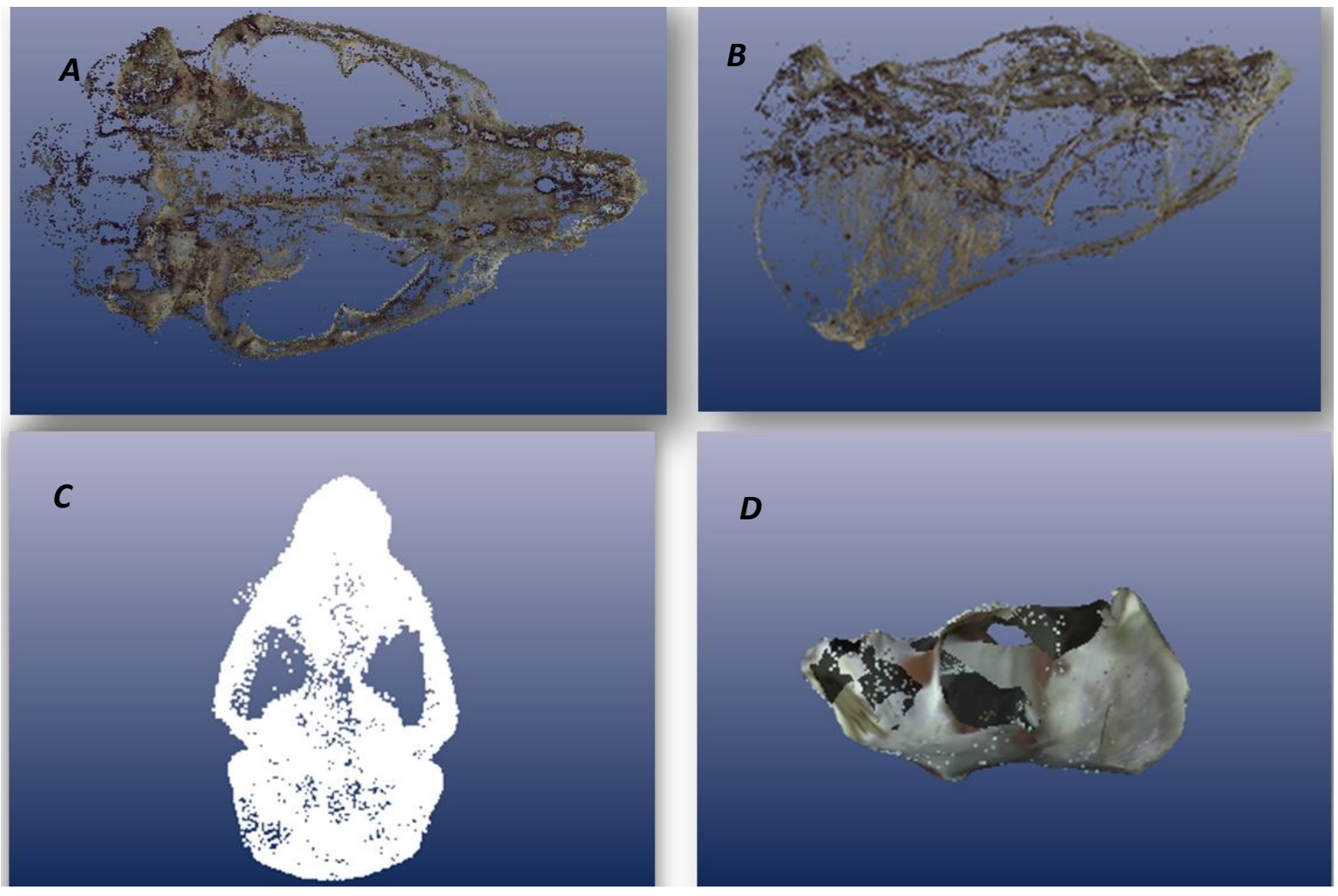

Figure 3. Set of 3D modelling at various stages of processing using Photomodeler Scanner $\AA$, A, Initial stage of natural skull features extraction, B, Three-dimensional modelling of the natural features, C, 3D skull in the default and dots surface layer, $\mathrm{D}$, partially complete 3D model used for measurements. 


\section{DISCUSSION}

The results show acceptable recordings for both tools used for 3D modelling. Both coded target (CT) and SmartMatch ${ }^{\circledR}$ (SM) methods (tools) worked well in constructing the 3D skull models. Alby et al. (2009) also produced smooth 3D models with PMSc®. Both tools worked equally well at ambient light. However with the coded target, it is necessary to initially standardize the experimental structure as an integral part of the photography and has to remain stable throughout the experimentation. The SmartMatch ${ }^{\circledR}$ on the other hand only requires good lighting condition without rigorous setups and is more user-friendly as compared to the coded target. Due to the required degree of constant stability of the experimentation structure, the coded target project is more susceptible to unintended human errors. However, both methods do not have too many intensive needs for the operation of modelling.

In terms of time required to obtain the final 3D skull model, the SmartMatch ${ }^{\circledR}$ method is more effective than the coded target method. The PMSc $®$ models reached submillimetric precision (Jordan et al. 2001, Alby et al. 2009), as the SmartMatch ${ }^{\circledR}$ picks up minute details of the natural features on the skulls and automatically performs the referencing, then arranges the images in $3 \mathrm{D}$ modelling format (Fig 3,4). Importantly, this minute detail capture is derived from the camera/lens resolution available from the camera.

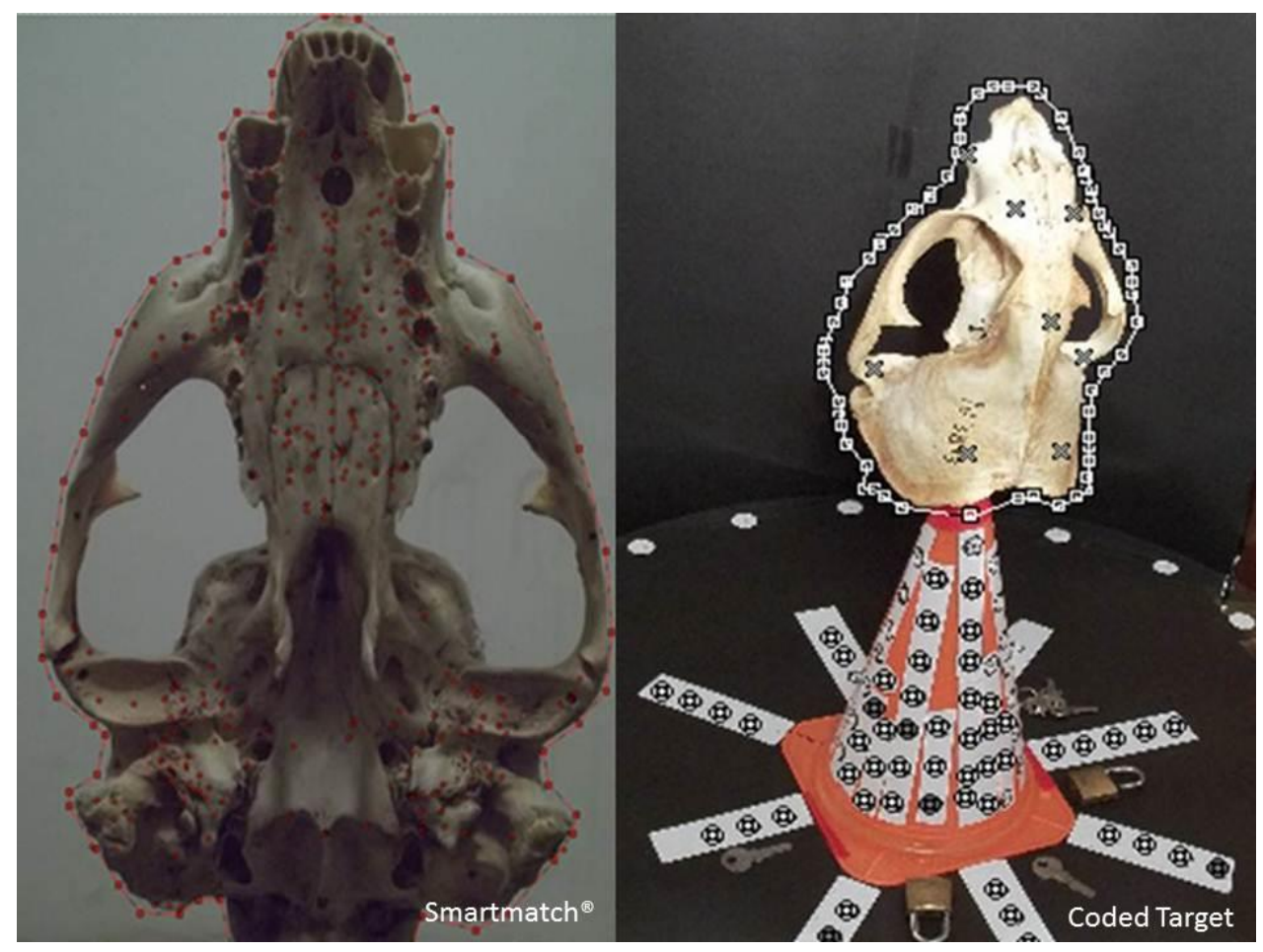

Figure 4. SmartMatch ${ }^{\circledR}$ and coded target images during fur seal skulls $3 \mathrm{D}$ acquisition

Although these two tools share common stages of processing, it also differs in the degree of manual operation required to attain the final $3 \mathrm{D}$ model. The four main reasons that the coded target was used in projects are: a) to automate 3D point measurement using Automated coded targets, b) to increase the speed at which projects can be completed, and robustness of the crucial orientation stage in projects that use a mixture of coded and manually marked targets, and c) to improve robustness and reduce the chances of acquiring incorrectly referenced points. The successfully produced 3D models from the coded target were of a compromised resolution that might be attributed to large distances between the skull and the cameras. The large distances between the skull and the cameras resulted in images covering a large portion of the surrounding area where the skull was placed. Only approximately $10 \%$ of the image was occupied by the skull, and the photographs had an inadequate coverage (effectively utilizing only 1.4 megapixels of the available 14 megapixels). Although the resolution obtained at 1.4 megapixels was inadequate, a reduction of the distance between the cameras and the skull would promote maximization of the photograph coverage of the skull which could improve the results. The improvements of the photograph coverage in camera calibration could also be used to improve the results. The SmartMatch ${ }^{\circledR}$ tool is preferred because it automatically detects natural features in photos and reliably matches these features between photos. A photo-based scanner's accuracy and resolution are affected by the resolution of the camera used, the distance of the camera to the subject, and the nature of the texture and pattern on the skull surface. In addition, SmartMatch ${ }^{\circledR}$ requires little human or manual intervention which ensures more accuracy with less human errors. It also has a multi-purpose feature in that: 1) it gives quick project setup and orientation of all photos, 2) operates at low to medium density point clouds for analysis, measurement, and surfacing, and 3) uses point clouds for approximate surface setup as a precursor to Dense Scanning. The sum of factors that maximized the software tool of choice were camera calibration, the camera setup, total number of photographs taken, lighting conditions and sampling intervals. 


\subsection{Comparison: PMSc® and caliper.}

Measuring and calculating the skull metrics and $p$-values enabled a comprehensive evaluation of the PMSc® (Walford 2008) and traditional method (calipermeasurements) (Stewardson et al. 2008). Skull metrics can be precisely recorded by the two methods and the $p$-values indicated that PMSc® recordings and calliper recordings are comparable. This study has further demonstrated the high efficiency of the PMSc $\AA$ both in time and repeatability of recorded values. Therefore, the PMSc ${ }^{\circledR}$ produces very good 3D skull models which are true replicas of the actual skulls. This adds to the advantage of acquiring the biological information of organisms in their biological form or 3D configuration (Rohlf and Marcus 1993), thereby reducing the risk of losing critical information (Fadda et al. 1997). Compared with the traditional method measurements, the photogrammetry method is significantly more efficient and accurate (Wang et al. 2006). The PMSc ${ }^{\circledR}$ technique can benefit both linear and volumetric studies (Graff and Gharib 2008) as it is more adapted to any object dimension (Alby et al. 2009).

\section{CONCLUSION}

PMSc ${ }^{\circledR}$ produced the accurate and high-resolution, threedimensional (3D) models of fur seal skulls. The same approach can be applicable to another object of interest which may be considered for 3D modelling. This method also offers a non-invasive, time effective and cost effective (once software had been purchased) way to produce an accurate high resolution 3D model of a skull and offer exceptional options of recording different types of measurements from the models, which may be developed into volumetric measurements. Of particular interest is that in using this method, an entire museum specimen collection can successfully be digitized, the digital images and 3D models of these can be accessed at any locality and used by any number of researchers without requiring the actual specimen at hand. Future research should also be directed at collective mass and volume estimation of the digitised models.

\section{ACKNOWLEDGEMENT}

This study was funded by South African National Research Foundation (NRF). The authors are grateful to the Sealers of Marion Island and other researchers who collected the specimens. The authors are further grateful to Mr Patrick Abila and Ms Mukundi Mukundamago for reviewing the manuscript.

\section{REFERENCES}

Alby, E., Smigiel, E., Assali, P., Grussenmeyer, P., Kauffmann-Smigiel, I., 2009. Low cost solutions for dense point clouds of small objects: PhotoModeler Scanner vs. David Laserscanner. 22nd CIPA.

Becerra, J.M., Bello,E., Garcia-Valdecasas, A., 1993. Building your own machine image system for morphometric analysis: A user point of view. In: Leslie F. Marcus, Elisa Bello AG-V (ed) Contributions to morphometrics, 1st edn. Madrid: Museo Nacional de Ciencias Naturales, C.S.I.C., Madrid, p 65-92.

Bester, M.N., Van Jaarsveld, A.S., 1994. Sex-specific and latitudinal variance in postnatal growth of the Subantarctic fur seal (Arctocephalus tropicalis). Canadian Journal of Zoology 72: 1126-1133.

Chiari, Y., Claude, J., 2011. Study of the carapace shape and growth in two Galápagos tortoise lineages. $\mathbf{J}$ Morphol 272:379-86.

Claude, J., Paradis, E., Tong, H., Auffray, J., 2003. A geometric morphometric assessment of the effects of environment and cladogenesis on the evolution of the turtle shell Testudinoidea. Society:485-501.

Croxall, J.P., Prince, P.A., 1979. Antarctic Seabird and Seal Monitoring Studies. Polar record 19: 573595.

de Bruyn, P.J.N., Bester, M.N., Carlini, A., Oosthuizen, W., 2009. How to weigh an elephant seal with one finger: a simple three-dimensional photogrammetric application. Aquat Biol 5:31-39.

Dean, D., 1996. Three-dimensional data capture and visualization. In: Marcus L, Corti M, Loy A, Naylor G SD (ed) Advances in morphometrics, 1st edn. Plenum Publishing Corp, New York, USA, p 284.

Deng, G., Falg, W., 2001. An Evaluation of an Off-theshelf Digital Close- Range Photogrammetric Software Package. Photogramm Eng Remote Sens 67:227-233.

Fadda, C., Faggiani, F., Corti, M., 1997. A portable device for the three dimensional landmark collection of skeletal elements of small mammals. Mammalia 4:622-627.

Gauthier, O., Landry, P.A., Lapointe, F.J., 2003. Missing data in craniometrics: a simulation study. Acta Theriol (Warsz) 48:25-34

Graff, E.C., Gharib, M., 2008. Performance prediction of point-based three-dimensional volumetric measurement systems. Meas Sci Technol 19:075403.

Ifflaender, S., Rüdiger, M., Koch, A., Burkhardt, W., 2013. Three-dimensional digital capture of head size in neonates - a method evaluation. PLoS One 8:e61274.

Jordan, P., Willneff, J., Apuzzo, N.D., Weishaupt, M., Wistner, T., Auer, J., 2001. Photogrammetric measurement of deformations of horse hoof horn capsules. Methods 4309:204-211.

Lu, X., 2003. Postnatal growth of skull linear measurements of Cape Hare Lepus capensis in northern China: an analysis in an adaptive context. Biological Journal of the Linnean Society 78: 343353.

Marcus, L., Bello, E., García-Valdecasas, A., 1993. Contributions to morphometrics.

McLean, G., Coombs, P., Sehgal, A., Paul, E., Zamani, L., Gilbertson, T., Ptasznik, R., 2012. Measurement of the Lateral Ventricles in the Neonatal Head: Comparison of 2-D and 3-D Techniques. Ultrasound Med Biol 38:2051-2057.

Poroshin, E.A., Polly, P.D., Wójcik, J.W., 2010. Climate and morphological change on decadal scales: Multiannual variation in the common shrew Sorex araneus in northeast Russia. Acta Theriologica 55: 
193-202.

Remondino, F., Fraser, C., 2006. Digital camera calibration methods: considerations and comparisons. International Society for Photogrammetry and Remote Sensing 36:266-272.

Rohlf, F., Bookstein, F., 1990. Proceedings of the Michigan morphometrics workshop (Fink SV, Ed.), Special Pu. Ann Arbor, Michigan.

Rohlf, F.J., 1990. Morphometrics. Annu Rev Ecol Syst 21:299-316.

Rohlf, F.J., Marcus, L., 1993. A revolution morphometrics. Trends Ecol Evol 8:129-132.

Sholts, S.B., Wärmländer, S.K.T.S., Flores, L.M, Miller, K.W.P., Walker., Phillip, L., 2010. Variation in the measurement of cranial volume and surface area using 3D laser scanning technology. J Forensic Sci 55:871-6.

Spencer, M.A., Spencer, G.S., 1995. Technical note: Video-based three-dimensional morphometrics. American Journal of Physical Anthropology 96: 443-453.

Stevens, W.P., 1997. Reconstruction of three-dimensional anatomical landmark coordinates using video-based stereophotogrammetry. Journal of anatomy 191 ( Pt 2: 277-84.

Stewardson, C.L., Prvan, T., Meyer, M.A., Ritchie, R.J., 2008. Age Determination and Growth in the Male South African Fur Seal Arctocephalus pusillus pusillus (Pinnipedia: Otariidae) Based upon Skull Material. In: Proceedings of the Linnean Society of New South Wales.p 207-252

van der Niet, T., Zollikofer, C.P.E., León. M.S.P., De Johnson, S.D., Linder, H.P., 2010. Threedimensional geometric morphometrics for studying floral shape variation. Trends in plant science 15: 423-6.

Walford, A., 2008. A new way to 3D scan. White paper. White paper Eos Systems

Wang, Q., Strait, D.S., Dechow, P.C., 2006. Fusion Patterns of Craniofacial Sutures in Rhesus Monkey Skulls of Known Age and Sex from Cayo Santiago. 485:469-485

Wigginton, J.D., Dobson, F.S., 1999. Environmental influences on geographic variation in body size of western bobcats. Small 813: 802-813.

Zelditch, M.L., Swiderski, D.L., Sheets, H.D., Fink, W.L., 2004. Geometric Morphometrics for Biologists: A Primer. 95:1-5.

Zollikofer, C.P.E., Ponce De, León, M.S., 2002. Visualizing patterns of craniofacial shape variation in Homo sapiens. Proc Biol Sci 269:801-7. 